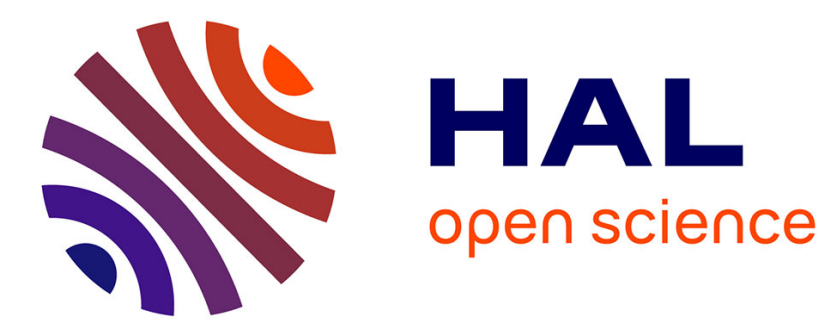

\title{
The inner heterogeneity of ZSM-5 zeolite crystals
}

Yanfeng Shen, Zhengxing Qin, Shunsuke Asahina, Natsuko Asano, Guanqun

Zhang, Shuya Qian, Yanhang Ma, Zifeng Yan, Xinmei Liu, Svetlana Mintova

\section{To cite this version:}

Yanfeng Shen, Zhengxing Qin, Shunsuke Asahina, Natsuko Asano, Guanqun Zhang, et al.. The inner heterogeneity of ZSM-5 zeolite crystals. Journal of Materials Chemistry A, 2021, 10.1039/D0TA11023J . hal-03145242

\section{HAL Id: hal-03145242 \\ https://hal.science/hal-03145242}

Submitted on 18 Feb 2021

HAL is a multi-disciplinary open access archive for the deposit and dissemination of scientific research documents, whether they are published or not. The documents may come from teaching and research institutions in France or abroad, or from public or private research centers.
L'archive ouverte pluridisciplinaire HAL, est destinée au dépôt et à la diffusion de documents scientifiques de niveau recherche, publiés ou non, émanant des établissements d'enseignement et de recherche français ou étrangers, des laboratoires publics ou privés. 


\section{The inner heterogeneity of ZSM-5 zeolite crystals}

Yanfeng Shen, ${ }^{\mathrm{a}}$ Zhengxing Qin, ${ }^{\text {a }}$ Shunsuke Asahina, ${ }^{\mathrm{b}}$ Natsuko Asano, ${ }^{\mathrm{b}}$ Guanqun Zhang, ${ }^{\mathrm{c}}$ Shuya Qian, ${ }^{\mathrm{a}}$ Yanhang $\mathrm{Ma},{ }^{\mathrm{c}}$ Zifeng Yan, ${ }^{\mathrm{a}}$ Xinmei Liu, ${ }^{\mathrm{a}}$ and Svetlana Mintova ${ }^{{ }_{\mathrm{a}, \mathrm{d}}}$

Abstract: The inner architecture of zeolite crystals beneath the zeolite surface is the missing part in understanding the crystallization of zeolites and in their thoughtful post-synthesis engineering. In this work, both the defect-zoning and Al-zoning in pseudo-single ZSM-5 crystals were revealed using unbiased $\mathrm{NH}_{4} \mathrm{~F}$ etching of as-synthesized and calcined samples. The formation of defect-zoning leading to multiple core-shell structure was described with a three-stage process involving (i) nucleation resulting in the innermost core formation, (ii) fast aggregate growth leading to defect-rich zones, and (iii) layer-by-layer growth shaping the final morphology of the zeolite crystals. A clear correlation between $\mathrm{Al}$ zoning and the spatial distribution of $\mathrm{C}$ and $\mathrm{Na}$ was established. This distinct inner heterogeneity in the ZSM-5 crystals reveals the particularities of the crystal growth process of this very important zeolite, and this knowledge can be translated into novel framework structures with targeted properties.

\section{Introduction}

Zeolites are widely used as catalysts or adsorbents in many commercial processes. In the future, their impact is expected to be broaden, especially in the processing of fossil fuels and a variety of new feedstocks. ${ }^{[1-3]}$ The tailored design of efficient zeolite materials for these diversified applications depends greatly on the deep understanding of the arrangement details of the internal components of zeolite crystals that determine their properties and potential applications.

The complex crystal growth process of zeolites is represented as a synergy between solution mediated and solid-phase transformation. ${ }^{[4-7]}$ Extensive microscopic and spectroscopic study of the intermediate and final products led to a substantial understanding of the zeolite crystal growth process. ${ }^{[8-14]}$ For example, atomic force microscopy and scanning microscopy provided dynamic surface morphology information at nanoscale level and evidence for layer-by-layer growth and crystallization of MFI, LTA, CHA zeolites via oriented nano-particle attachment. ${ }^{[14-17]}$ The spatial heterogeneities in crystallographic orientation and chemical composition of MFI and FER zeolites were revealed as well. ${ }^{[18-22]}$ The structural investigation using X-ray diffraction gives key insights into the size of the coherent domains, the unit cell volume, the modification of space groups, and the presence of lattice imperfections and strain of MFI and FAU zeolites. ${ }^{[23-25]}$ Besides, time-resolved multinuclear ${ }^{13} \mathrm{C},{ }^{23} \mathrm{Na},{ }^{27} \mathrm{Al}$, and ${ }^{29} \mathrm{Si}$ MAS NMR spectroscopy have also been applied for monitoring the mechanistic pathways of BEA and FAU zeolites. ${ }^{[6,26]}$ By using high resolution transmission electron microscopy, the entire sequence of crystallization events in LTA-type zeolite has been monitored. ${ }^{[27]}$ We recently revealed the twinning and the hidden "mosaic" structure of MFI and MOR zeolite crystals. ${ }^{[7]}$

Despite these findings the comprehensive understanding of zeolite crystallization from atomistic arrangements to ultimate (maturated) zeolite crystals is still under discussion. The main methods applied up to now either average information over the entire volume of the zeolite sample or partially visualize the outermost surface of zeolite crystals. Understanding the inner architecture beneath zeolite surface is of crucial importance for the tailored-design of zeolites. The questions that need to be answered are as follows: (i) how the 2D self-assembly of low-weight molecules and 3D 
attachment of oriented particles compete and cooperate in a dynamic inhomogeneous system leading to crystal growth; (ii) what is the consequence of such concerted actions on the structure of zeolite crystals especially in the presence of structure building units of different properties (chemical composition, particle size, solubility) coexisting with organic and inorganic structure-directing agents having different stereospecificity and charging properties; (iii) to which extent the reaction system can be considered as inhomogeneous; and (iv) how the heterogeneity of the precursor inherited into the final zeolite product.

Herein, we reveal the inner structural details and the spatial elements distribution of MFI type zeolite crystals, and explore the underlying mechanisms leading to the inhomogeneous structure formation. In contrast to in situ studies of crystals growth process of zeolites reported up to now, we based our study on matured zeolite crystals subjected to "top-down" post-synthesis chemical treatment. ${ }^{[7]}$ Detailed analysis of the internal architecture of these zeolite crystals provides unique insights into zeolite crystallization process and reveals the ubiquitous presence of defect-zoning and Al-zoning in zeolite crystals.

\section{Experimental Section}

\subsection{Materials preparation}

\subsubsection{Synthesis of ZSM-5 crystals}

For the zeolite synthesis, all chemicals were purchased from Sinopharm Chemical Reagent Corporation and used directly without further purification. $2.5 \mathrm{~g}$ sodium hydroxide $(\mathrm{NaOH}, 96 \mathrm{wt} . \%)$ and $20.3 \mathrm{~g}$ tetrapropylammonium hydroxide (TPAOH, 25 wt.\%) were first dissolved in $450 \mathrm{~g}$ deionized water in a polypropylene bottle at room temperature under magnetic stirring. Then $3.75 \mathrm{~g}$ aluminum nitrate $\left(\mathrm{Al}\left(\mathrm{NO}_{3}\right)_{3} \cdot 9 \mathrm{H}_{2} \mathrm{O}, 99 \mathrm{wt} . \%\right)$ was added into the alkaline solution, followed by the adding of $52 \mathrm{~g}$ tetraethyl orthosilicate (TEOS, 28.4\% calculated as $\mathrm{SiO}_{2}$ ). The mixture was kept at room temperature under magnetic stirring overnight to ensure the hydrolysis of TEOS. The final molar ratio of the synthesis gel was as followed: $0.125 \mathrm{Na}_{2} \mathrm{O}: 0.05$ (TPA) $2 \mathrm{O}: 0.02 \mathrm{Al}_{2} \mathrm{O}_{3}: 1.0 \mathrm{SiO}_{2}: 100 \mathrm{H}_{2} \mathrm{O}$. Then, the mixture was transferred into a Teflon-lined stainless steel autoclave and heated in an oven at $443 \mathrm{~K}$ for $36 \mathrm{~h}$. Intermediate and final products were subjected to separation by high speed centrifuge (30000 r/min, 30 min, Beckman Avanti JXN-30), washed thoroughly, and dried in a freeze dryer. The ZSM-5 zeolite sample collected in the end of synthesis was denoted as $Z_{\mathrm{P}}$. The variation of $\mathrm{pH}$ in the gel during crystallization process was monitored by testing the liquid phase after separation from the reacted mixture by centrifugation.

$\mathrm{Co}^{2+}$-exchanged zeolites were prepared according to the following procedures. First, $2 \mathrm{~g}$ calcined zeolite sample was experienced sodium ion exchange by a $\mathrm{NaCl}$ (Sinopharm Chemical Reagent Corporation, 99.8\%) solution with weight ratio as follows: $1.0 \mathrm{~g}$ zeolite: $1.0 \mathrm{~g} \mathrm{NaCl}: 10.0 \mathrm{~g} \mathrm{H}_{2} \mathrm{O}$. This process was performed at $363 \mathrm{~K}$ for $3 \mathrm{~h}$ and repeated three times before washing. The obtained Na-form ZSM-5 zeolite was dried at $373 \mathrm{~K}$ overnight and then dispersed into a $0.05 \mathrm{M} \mathrm{Co}\left(\mathrm{NO}_{3}\right)_{2}$ solution with a weight ratio of $1: 10$ and ion-exchanged at room temperature for $6 \mathrm{~h}$ under stirring. To achieve complete exchange, the $\mathrm{Co}^{2+}$ exchange was repeated 3 times. The final exchanged sample was washed thoroughly and dried at $373 \mathrm{~K}$ overnight.

\subsubsection{Treatment of ZSM-5 crystals with $\mathrm{NH}_{4} \mathrm{~F}$}

The parent ZSM-5 zeolite (sample $\mathrm{Z}_{\mathrm{P}}$ ) was divided into 2 parts: one part (as-synthesized sample) was treated by $\mathrm{NH}_{4} \mathrm{~F}$ without removing the organic structural directing agent $\left(\mathrm{TPA}^{+}\right)$and the second part (calcined sample) was treated at $823 \mathrm{~K}$ in static air for $12 \mathrm{~h}$ with a temperature ramp of $6 \mathrm{~K} \mathrm{~min}^{-1}$. Subsequently the $\mathrm{NH}_{4} \mathrm{~F}$ treatment was carried out in 40 wt.\% ammonium fluoride solution $\left(\mathrm{NH}_{4} \mathrm{~F}, 96\right.$ wt.\%) at $323 \mathrm{~K}$ under stirring, with a solid/liquid ratio of 1: 30 . The 
$\mathrm{NH}_{4} \mathrm{~F}$ treatment time of the as-synthesized ZSM- 5 was $4 \mathrm{~h}$, and for the calcined ZSM- 5 was 1 or $2 \mathrm{~h}$. The treated zeolites were collected by vacuum filtration, washed with deionized water and dried at $373 \mathrm{~K}$ overnight. The sample obtained from the as-synthesized ZSM-5 after treatment with $\mathrm{NH}_{4} \mathrm{~F}$ will be abbreviated as $\mathrm{TPA}-\mathrm{Z}_{\mathrm{F}}$ thereafter.

\subsubsection{Synthesis and $\mathrm{NH}_{4} \mathrm{~F}$ etching of ZSM-5-H1 and ZSM-5-H2}

The first home-made ZSM-5 zeolite, ZSM-5-H1, was synthesized from an initial gel with a molar composition of 1.0 $\mathrm{SiO}_{2}: 0.01 \mathrm{Al}_{2} \mathrm{O}_{3}: 0.25$ TPAOH: $8.1 \mathrm{H}_{2} \mathrm{O}$. First, aluminum nitrate nonahydrate (99 wt. \%) was dissolved in an aqueous solution of tetrapropylammonium hydroxide (TPAOH, 25 wt. \%) to get a clear solution. Then colloidal silica (40 wt. \%, LUDOX HS-40, Sigma-Aldrich) was added slowly into the template-aluminum mixed solution. The resultant mixture was stirred for another $60 \mathrm{~min}$. Then the synthesis gel was loaded to a Teflon-lined stainless steel autoclave. The sealed autoclave was transferred into a preheated air-circulated oven and heated at $443 \mathrm{~K}$ under static conditions. After 7 days the autoclave was removed from the oven and quenched immediately with cool tap water. Solid material was recovered by centrifugal separation and washed with distilled water until the $\mathrm{pH}$ of the wash was approximately 7.0. The solid product was then recovered and dried at $373 \mathrm{~K}$ overnight. The template was removed by calcination at $823 \mathrm{~K}$ for 12 $\mathrm{h}$ with a ramp of $2 \mathrm{~K} / \mathrm{min}$.

The composition (molar ratio) of initial gel for the preparation of the second home-made ZSM-5 zeolite, ZSM-5-H2, was as followed: $1.0 \mathrm{SiO}_{2}: 0.01\left[\left(\mathrm{CH}_{3}\right)_{2} \mathrm{CHO}\right]_{3} \mathrm{Al}: 0.491 \mathrm{TPAOH}: 0.118 \mathrm{KOH}: 30 \mathrm{H}_{2} \mathrm{O}$. First aluminum isopropoxide (98 wt\%, Fluka) was dissolved in an aqueous solution of tetrapropylammonium hydroxide (TPAOH, $20 \mathrm{wt} \%$, Alfa Aesar) and potassium hydroxide ( $85 \mathrm{wt} \%$, Sigma-aldrich) to get a clear solution. Another solution was prepared by mixing colloidal silica (40 wt\%, LUDOX HS-40, Sigma-Aldrich) with a proper amount of distilled water and added slowly into the template-aluminum mixed solution under stirring. The resultant mixture was stirred for another $60 \mathrm{~min}$. Then the synthesis gel was loaded to a $100 \mathrm{~mL}$ Teflon-lined stainless steel autoclave. The sealed autoclave was transferred into a preheated air-circulated oven and heated at $443 \mathrm{~K}$ under static conditions. After $48 \mathrm{~h}$ the autoclave was removed from the oven and quenched immediately with cool tap water. Solid material was recovered by vacuum filtration and subsequently washed with distilled water until the $\mathrm{pH}$ of the wash was approximately 7.0. The solid cake was then recovered and dried at $373 \mathrm{~K}$ overnight. The template was removed by calcination at $823 \mathrm{~K}$ for $6 \mathrm{~h}$ with a ramp of $1.5 \mathrm{~K} / \mathrm{min}$.
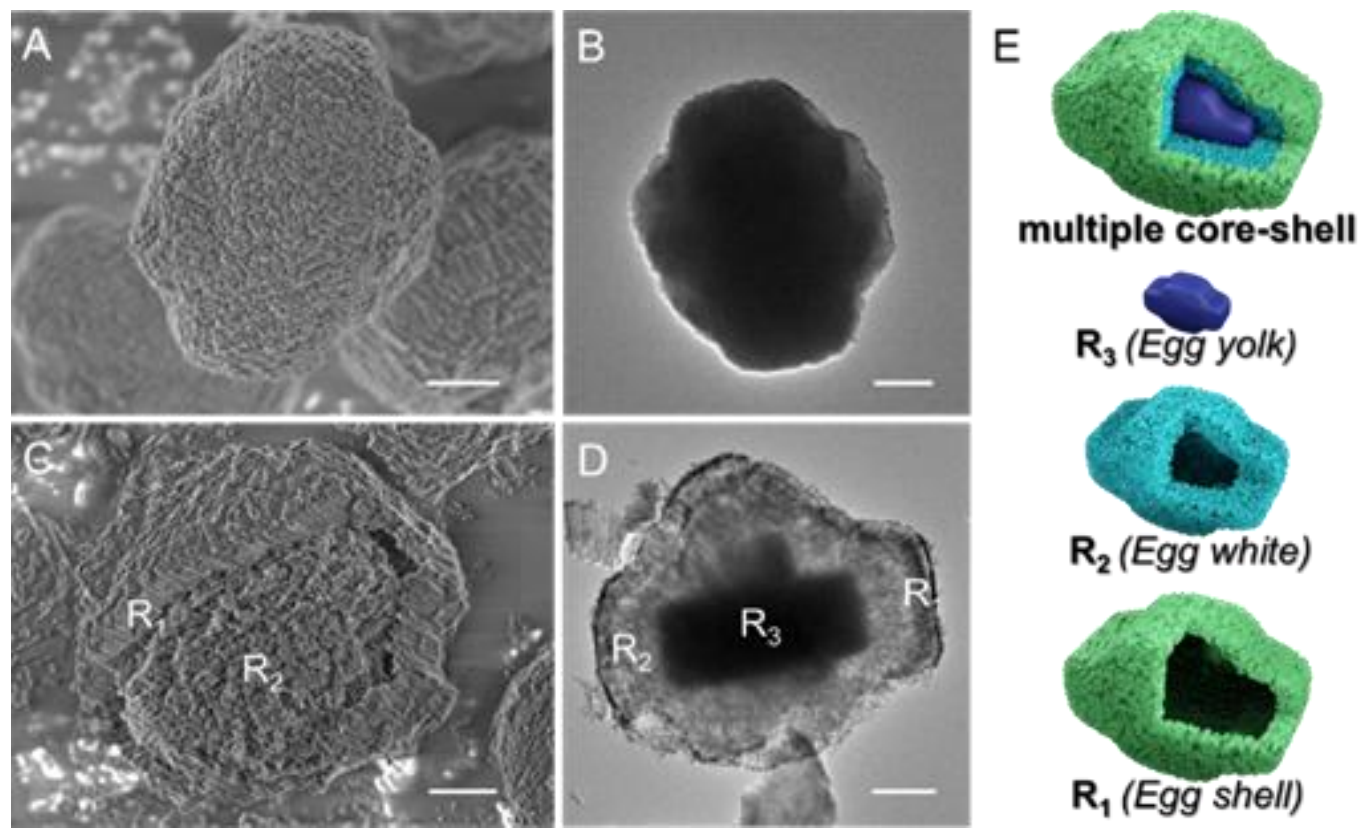

$\mathbf{R}_{\mathbf{1}}($ Egg shell) 
Figure 1. SEM (A) and TEM (B) images of parent ZSM-5 zeolite (sample $Z_{P}$ ), SEM (C) and TEM (D) images of ZSM-5 zeolite treated with $\mathrm{NH}_{4} \mathrm{~F}$ (sample TPA-Z $\mathrm{F}$ ), Scale bars in A-D are $1 \mu \mathrm{m}$. Illustration of the multiple core-shell structure of zeolite crystals (E), different layers of the core-shell structure are distinguished: $\mathrm{R}_{1}$ represents the outermost shell (“egg-shell”), $\mathrm{R}_{2}$ the highly segmented layer in the middle ("egg-white"), and $\mathrm{R}_{3}$ the innermost layer ("egg-yolk")

Fluoride medium etching was carried out follows precisely the same procedure as for the $\mathrm{NH}_{4} \mathrm{~F}$ treatment of the ZSM-5 zeolite in previous section.

\subsection{Characterization}

The X-ray diffraction (XRD) patterns of as-synthesized and post-treated zeolite samples were collected on a Bruker D8 Advance diffractometer equipped with $\mathrm{Cu} \operatorname{K} \alpha$ radiation $(\lambda=1.5418 \AA)$.

Scanning electron microscopy (SEM) images were taken with JSM-7900F (JEOL) electron microscope equipped with a field emission gun. The cross-section of zeolite samples was prepared by using an ion Beam cross-section polisher (IB-19510CP, JEOL). The zeolite crystals were fixed on a carbon tape prior preparation of the cross-sections. Then the cut samples were coated with osmium (Os) using a Filgen Os coater ( $3 \mathrm{~nm}$ thick) and the element mapping was recorded with a JSM-7900F SEM with an EDS detector (Oxford EDS $170 \mathrm{~mm}$ x2). The acceleration voltage, beam current and work distance for the SEM study were $5 \mathrm{kV}, 1.5 \mathrm{nA}$ and $10 \mathrm{~mm}$, respectively. In addition, the chemical composition of the zeolites was measured by XRF using an AXIOS-Petro X (PANalytical B.V.). The surface chemical composition (Si/Al ratios) of zeolite crystals was obtained by X-ray photoelectron spectroscopy (XPS) with a PHI 500 spectrometer using Al Ka radiation. Transmission electron microscopy (TEM) pictures were taken on a JEM-2100 (JEOL) with an accelerate voltage of $200 \mathrm{kV}$. Scanning transmission electron microscopy (STEM) images were taken on a JEOL JEM-F200 electron microscope with Gatan Rio 1816 (IS) camera, allowing a point resolution of $1.9 \AA$ under STEM mode, equipped with a JEOL SDD EDS detector $(100 \mathrm{~mm} 2 \times 1)$. All STEM images and EDS spectra were taken under an acceleration voltage of $200 \mathrm{kV}$.

The porosity of the samples was studied by Ar physisorption performed on an Auto-sorb iq3 (Quanta chrome) at 87 K. The $\mathrm{N}_{2}$ sorption isotherm of $\mathrm{Na}^{+}$exchanged TPA-Z $\mathrm{F}$ was also performed on the Auto-sorb iq3 (Quanta chrome) at 77 K. The size of particles in initial amorphous gels used for the preparation of ZSM-5 crystals was measured by dynamic light scattering (DLS) using a Malvern Nano ZS instrument.

\section{Results}

\subsection{The multiple core-shell structure of zeolite crystals}

The crystalline parent ZSM-5 zeolite $\left(Z_{\mathrm{P}}\right)$ with uniform particle size distribution are presented in Figures S1. All individual crystallites show a polycrystalline morphology consisting of densely packed nanosized crystals (Figure 1A and Figure S1B-D). Both the TEM and STEM images show a homogeneous contrast of the zeolite crystals, indicating the absence of textured structures (Figure 1B, Figure 2A-C). The characteristic coffin shape for MFI type zeolite are shown in Figure S1D. 

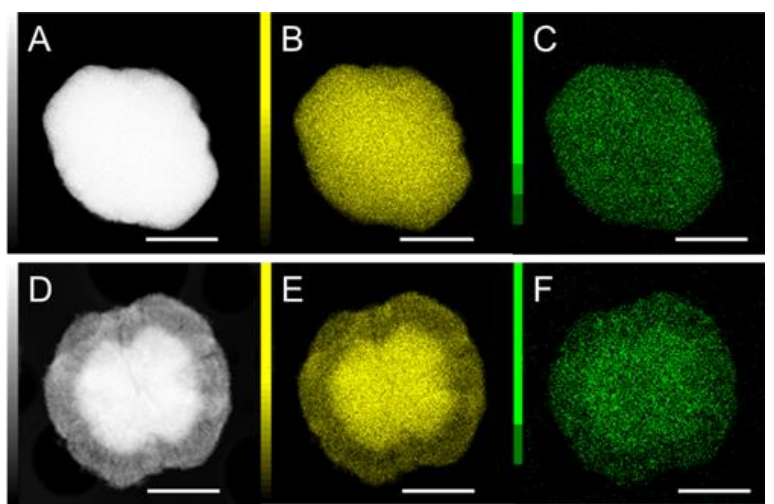

Figure 2. $S T E M$ images of $Z_{P}(A)$ and TPA- $Z_{F}(D)$, and STEM-EDS mapping images of $Z_{P}(B: S i, C: A l)$ and TPA-Z (E: Si, F: Al), Scale bar $=2 \mu \mathrm{m}$.
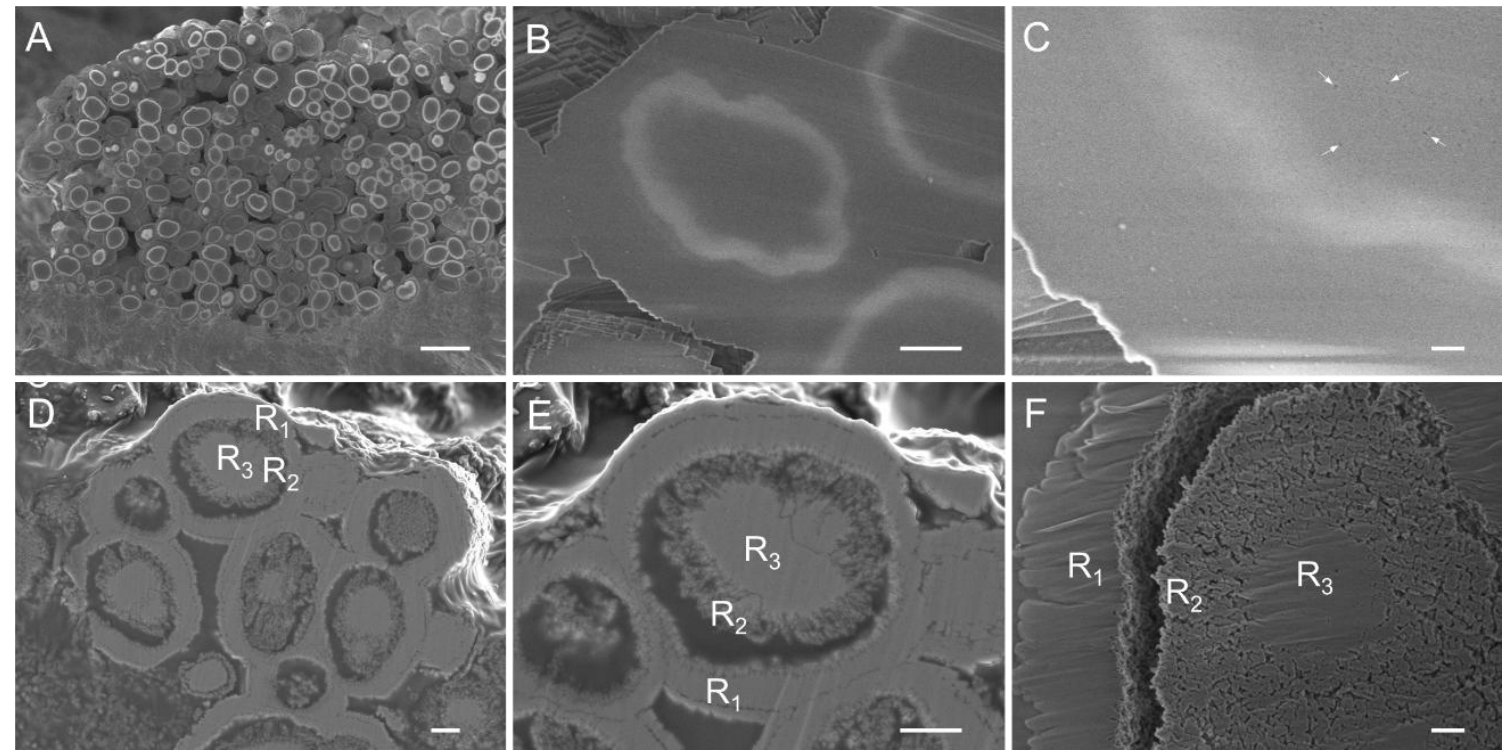

Figure 3. Cross section SEM images of the parent ZSM-5 zeolite crystals (sample $\mathrm{Z}_{\mathrm{P}}, \mathrm{A}-\mathrm{C}$ ) and $\mathrm{NH}_{4} \mathrm{~F}$ treated $\mathrm{ZSM}-5$ zeolite crystals (sample TPA-Z, D-F) at different magnification, scale bars: $10 \mu \mathrm{m}(\mathrm{A}), 1 \mu \mathrm{m}(\mathrm{B}, \mathrm{D}$ and E), $200 \mathrm{~nm}(\mathrm{C}$ and F). The white arrows indicate the presence of voids in the zeolite crystal volume.

The polycrystalline ZSM-5 zeolite $\left(\mathrm{Z}_{\mathrm{P}}\right)$ was treated by $\mathrm{NH}_{4} \mathrm{~F}$ without removing the organic template $\left(\mathrm{TPA}^{+}\right)$. The chemical treatment of the template-containing zeolite results in a zeolitic material (TPA-Z $\mathrm{F}_{\mathrm{F}}$ ) with preserved crystallinity (Figure S2) and a distinct core-shell structure (Figure 1C, Figure S3). While the core part (R $\mathrm{R}_{2}$, Figure 1C) appears as an assembly of numerous nano-sized nanoparticles, the shell $\left(\mathrm{R}_{1}\right.$ in Figure $\left.1 \mathrm{C}\right)$ is more united, with a homogeneous orientation of crystals with an even thickness. The zeolite crystals formed a polycrystalline shell (outermost "egg-shell”), with a thickness of about 1 micron (Figure $1 \mathrm{C}$, Figure S3). Additionally, two layers $\left(\mathrm{R}_{2}\right.$ and $\left.\mathrm{R}_{3}\right)$ can be clearly seen of the crystals (Figure 1D, Figure 2D-F and Figure S4). $\mathrm{R}_{2}$ represents a highly segmented layer in the middle ("egg-white") of the TPA- $Z_{F}$ crystals, while the $R_{3}$ represents the innermost layer ("egg-yolk"). The core $\left(R_{3}\right.$ in Figure 1$)$ is the most integrated one with either an elliptical or rectangular shape (Figure S4). This part, with a homogeneous and striking contrast, reveals the less porous nature of this area (Figure 1D, Figure 2D-F and Figure S4). To summarize, the TPA-Z zeolite has a distinct multiple core-shell structure as schematically presented in Figure 1E.

Details of the architecture of the multiple core-shell structures are provided by cross-section of $Z_{P}$ and TPA-Z 
crystals (see Experimental section). The structural details of these samples are revealed using ultra-high-resolution FE-SEM performed on coated (Figure 3D, E) and uncoated (Figure 3A-C and F) samples with a conductive layer. The multi-layer core-shell structure of TPA-Z $Z_{\mathrm{F}}$ zeolite is clearly seen in the cross-section SEM pictures shown in Figure 3D-F. This observation is consistent with the TEM and STEM results (Figure 1D, Figure 2 and Figure S4). Thus all the SEM, TEM, and STEM results confirmed the egg-like structure with multiple core-shell architectures of the TPA-Z $Z_{\mathrm{F}}$ zeolite.

No core-shell structure in the parent ZSM-5 zeolite (sample $Z_{P}$ ) is observed, although the cross-section SEM pictures contain a white "O-ring" (Figure 3A, B). Obviously, the $\mathrm{NH}_{4} \mathrm{~F}$ treatment caused the formation of the multiple core-shell structure of sample TPA- $Z_{\mathrm{F}}$. The white "O-ring” area can be considered as the boundary separating two zeolitic zones with different solubilities in fluoride media. This finding is based on the perfect matching of size and morphology of crystals of $Z_{P}$ and $T P A-Z_{F}$ shown in Figures 1-3 and Figures S1, S3, S4. The dissolution front propagation is inward since the dissolution of the periphery of the middle layer $\left(\mathrm{R}_{2}\right)$ is notable (Figure $1 \mathrm{C}$-D, Figure 3D-F).

\subsection{The spatial distribution of elements in zeolite crystals}

Table 1. EDX relative content of elements at selected zones (Figures 4A, C) for samples $Z_{P}$ and TPA-Z $Z_{F}$ (errors shown in parentheses).

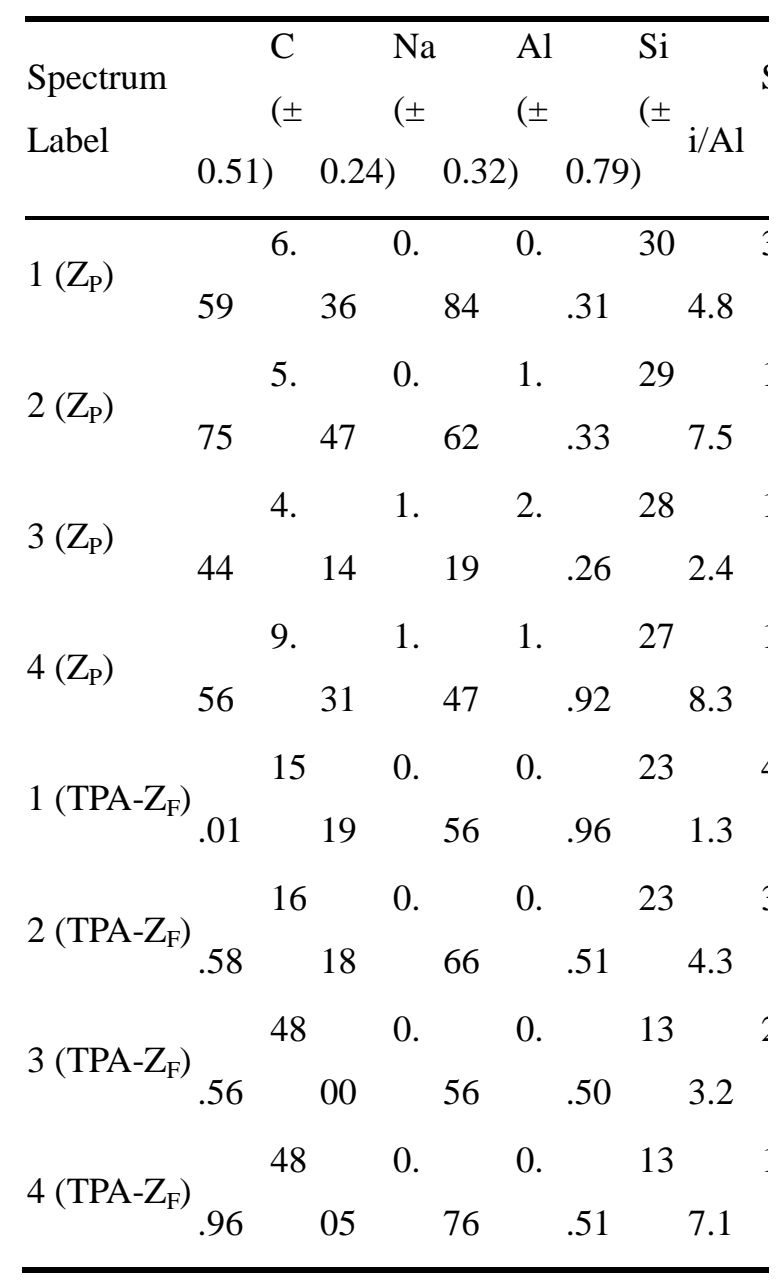




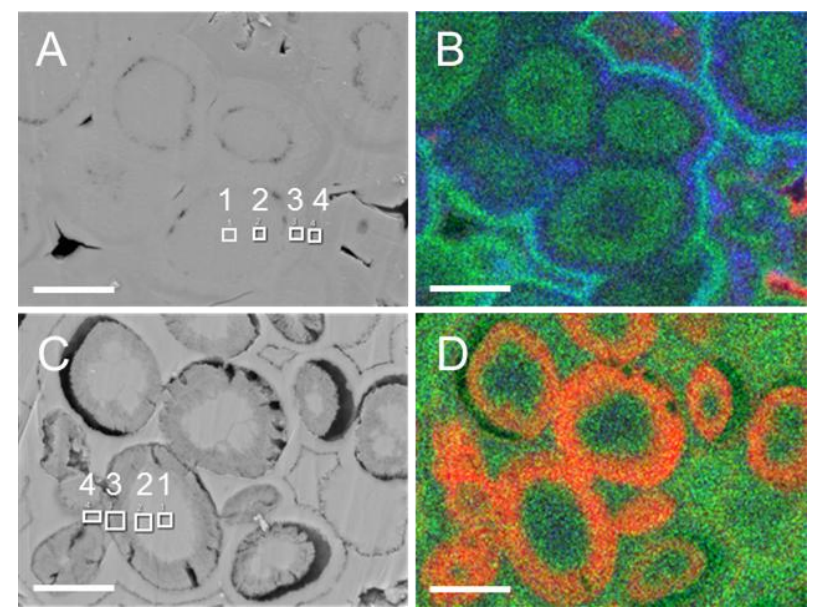

Figure 4. SEM-EDX mapping of the parent $\left(\mathrm{Z}_{\mathrm{P}}\right)$ and post treated $\left(\mathrm{TPA}-\mathrm{Z}_{\mathrm{F}}\right) \mathrm{ZSM}-5$ zeolites $($ Scale bar $=2.5 \mu \mathrm{m})$ : $(\mathrm{A})$ SEM image of sample $Z_{\mathrm{P}}$, (B) EDX mapping of sample $Z_{\mathrm{P}}$, (C) SEM image of sample TPA- $Z_{\mathrm{F}}$ and (D) EDX mapping of sample TPA- $Z_{\mathrm{F}}$. The EDX mapping presented in (B) and (D) show overlapping of different elements: sodium (blue), carbon (red) and aluminum (green). Inset: point analysis of the chemical composition in zones 1,2,3 and 4 performed and results are summarized in Table 1. Note: there is no one-to-one correspondence between Zones $R_{1}, R_{2}$, and $R_{3}$ in Figures 1 and 3 and Zones 1, 2, 3, 4 shown here and in Table 1.

The Si/Al ratio of the parent ZSM-5 (sample $\mathrm{Z}_{\mathrm{P}}$ ) is 20.3, according to the XRF analysis. It increases to 23.5 for sample TPA-Z $\mathrm{Z}_{\mathrm{F}}$ obtained after the $\mathrm{NH}_{4} \mathrm{~F}$ treatment. The "dealumination" phenomenon during the chemical treatment of zeolites in concentrated fluoride medium was already reported. ${ }^{[28]}$ However, the used $\mathrm{NH}_{4} \mathrm{~F}$ treatment is not $\mathrm{Si}$ or $\mathrm{Al}$ biased. ${ }^{[7,29,30]}$ This motivated us to perform mapping of spatial elements distribution within zeolite crystals before and after the $\mathrm{NH}_{4} \mathrm{~F}$ treatment since not a selective extraction of elements from the parent zeolite is expected. An EDX mapping of coated zeolite crystals with a $3 \mathrm{~nm}$ thick Os layer is carried out. Os, instead of other conductive layers (Au, C, $\mathrm{Pt}$ ) was applied for enhancing the conductivity of the specimen and for the precise detection of the carbon signal. The penetration depth was $100 \mathrm{~nm}$ under the applied conditions (see experimental section). The relative content of elements where the analysis was performed was normalized and calculated in atomic \% (Table 1). The corresponding SEM-EDX mapping and elemental point analysis data are shown in Figures 4, S5-S7.

The EDX mapping results provide the following important information: (i) All crystals of the parent sample have higher $\mathrm{Si}$ content in the core part, then the $\mathrm{Si} / \mathrm{Al}$ ratio decreases outward. This observation is valid for all crystals regardless of their particle sizes (Figure 4A, B). This tendency is clearly illustrated from the point analysis showing that the $\mathrm{Si} / \mathrm{Al}$ ratio decreased from 34.8 to 12.4 from zone 1 to zone 3 (Table 1). At the same time, there is a systematic decrease of carbon and an increase of Na from the core to the periphery of the crystals (Figures S5, S6). (ii) Similar zoned distribution of $\mathrm{Si}$ and $\mathrm{Al}$ was recorded for the post-treated zeolite TPA-Z $\mathrm{F}_{\mathrm{F}}$ (Figures 4C, D and Figures S5, S7); a general increase of the $\mathrm{Si} / \mathrm{Al}$ ratio of the sample is measured (Table 1). Both the EDX and XRF show similar results. (iii) All zones of the treated sample, with different degrees of dissolution, indicate lower $\mathrm{Na}^{+}$content than the parent sample (Table 1). Especially, the selected zone labelled as "3" in Figure $4 \mathrm{C}$ has no essential $\mathrm{Na}^{+}$(see Table 1). This zone 3 corresponds to the " $\mathrm{R}_{2}$ " shown in Figures 1 and 3. This observation is important, in particular, considering that the domain size of zeolite crystals is still about $50 \mathrm{~nm}$ large ( 25 unit cells) despite being heavily dissolved (Figure S4). 
This result points out that most of the charge compensating cations $\left(\mathrm{Na}^{+}\right)$in the zeolite are exchangeable, even though the $\mathrm{TPA}^{+}$counter cations block parts of zeolite framework. (iv) The $\mathrm{TPA}^{+}$concentration increases substantially in the sample after the $\mathrm{NH}_{4} \mathrm{~F}$ treatment (TPA-Z $\mathrm{Z}_{\mathrm{F}}$ ), especially in the $\mathrm{R}_{2}$ zone (Table 1, Figures S5, and S7). It is worth noticing that the samples were washed thoroughly after the $\mathrm{NH}_{4} \mathrm{~F}$ treatment. Thus, the deposition of $\mathrm{TPA}^{+}$containing salts on the zeolite crystals is not due to insufficient washing.

\section{Discussion}

The structural characteristics of a zeolite crystal dictates its dissolution behavior during the post-synthesis treatment and vice versa. ${ }^{[7,28]}$ Based on the results presented above, a detailed discussion will be held about the underlying mechanism leading to the selected-area dissolution behavior, and about the ultimate synthetic cause for the core-shell structure and Al-zoning formation.

\subsection{The mechanism leading to selected-area dissolution}

\section{A) Defect-zoning}

The spatially inhomogeneous dissolution of zeolite crystals has been reported by us before. Namely, the inner part of zeolite crystals is preferentially dissolved, while an outermost crust is resistant to $\mathrm{NH}_{4} \mathrm{~F}$ treatment. ${ }^{[30]}$ However, such unique zeolite crystals with a multiple core-shell structure was never reported before. We believe that two factors, in addition to the $\mathrm{NH}_{4} \mathrm{~F}$ treatment, are responsible for the formation of this unique multiple core-shell architecture of ZSM-5 zeolites. First, the location of $\mathrm{TPA}^{+}$as a charge balancing cation in the MFI zeolite framework could play an important role. The dissolution of calcined $\mathrm{Z}_{\mathrm{P}}$ zeolite (free of $\mathrm{TPA}^{+}$) was carried out under the same $\mathrm{NH}_{4} \mathrm{~F}$ treatment conditions. In this case, the dissolution of zeolite crystals was much faster in the absence of TPA ${ }^{+}$. This can be confirmed by the low product yield even when the treatment time was reduced by a half or even more. For example, the sample yield is $50 \%$ after $1 \mathrm{~h} \mathrm{NH}_{4} \mathrm{~F}$ treatment in the absence of $\mathrm{TPA}^{+}$. In the case of the as-synthesized zeolites containing TPA the product yield is $55 \%$ after $4 \mathrm{~h} \mathrm{NH}{ }_{4} \mathrm{~F}$ treatment. The calcined ZSM-5 zeolite was deeply dissolved after the treatment, as shown in Figure S8. The outmost shell is totally removed (Figure S8A). The $\mathrm{R}_{2}$ zone is almost fully removed after the treatment (Figure S8C). Even the core zone was highly etched, as shown in the SEM (Figure S8B) and TEM (Figure S8C, D) images. While sample TPA- $\mathrm{Z}_{\mathrm{F}}$ containing the $\mathrm{TPA}^{+}$treated by $\mathrm{NH}_{4} \mathrm{~F}$ even for longer time contains intact core (Figures 2D, 3E and S4). Apparently, the presence of $\mathrm{TPA}^{+}$suppresses substantially the dissolution of zeolite crystals in the $\mathrm{NH}_{4} \mathrm{~F}$ medium. TPA ${ }^{+}$cations occupy the intersection position of straight and sinusoidal channels of MFI zeolite during crystallization. ${ }^{[31]}$ Thus the presence of TPA ${ }^{+}$disturbs the diffusion of active fluoride species inside the zeolite, and directs the dissolution possibly only from the external surface of crystals or from the extended interface between large intergrown particles (see more examples in section 3.3 bellow), following a reverse "layer-by-layer" dissolution mechanism. ${ }^{[30]}$

Alternatively, the dissolution process can spread via $\mathrm{Na}^{+}$-rich zones. Namely, now that most of the $\mathrm{Na}^{+}$is exchangeable, the fluoride treatment along the available ion exchange sites is the most plausible alternative. Previously, we have identified isolated rectangular cavities as large as $20 \mathrm{~nm}$ surrounded by pure zeolitic walls as a result of the preferential removal of hidden nanosized domains by $\mathrm{NH}_{4} \mathrm{~F}$ treatment. ${ }^{[7]}$ This is a sound proof that active fluoride species can diffuse, via the available micropores of MFI framework, into the inner part of zeolite crystal and dissolve the crystals from inside based on the weak zones present. ${ }^{[28,30]}$

While the presence of $\mathrm{TPA}^{+}$suppressing the dissolution of zeolite crystals is rationalized and the possible tuning effect of charge compensating cations on zeolite dissolution behavior is discussed, these results cannot explain the biased 
dissolution front yet. As at the beginning of dissolution, the spatial distribution of $\mathrm{Na}^{+}$and $\mathrm{TPA}^{+}$cations in the narrow region to be removed can be considered as homogeneous, and there is an equal chance for the adsorption of $\mathrm{TPA}^{+}$on either side of the dissolution front. Moreover, the $\mathrm{R}_{1}$ zone should dissolve more if the Na-zoning dominates the dissolution behavior, as the $\mathrm{Na}$ content is higher in the $\mathrm{R}_{1}$ than in the $\mathrm{R}_{2}$ zone (Table 1, Figure 4). The fact that the $\mathrm{R}_{2}$ zone is dissolved much more than $\mathrm{R}_{3}$ suggests that the dissolution front is inward-pointing.

This result suggests the second possible cause for forming a unique core-shell structure that can be the defect sites. We already reported that the dissolution in $\mathrm{NH}_{4} \mathrm{~F}$ medium starts preferentially from defects, including the interface between different crystallites domains. ${ }^{[7,29]}$ Therefore, the $\mathrm{R}_{2}$ zone has a much higher number of defects sites than the $\mathrm{R}_{1}$ zone. In agreement with this, the $R_{1}$ zone shows a much larger coherent domain size than the $R_{2}$ zone (Figure $S 9$ ). A careful inspection of the uncovered cross-section of $Z_{P}$ reveals the presence of meso-sized pores in the volume of crystals (Figure 3C). Moreover, it seems most, if not all, of the meso-sized holes are distributed inside of the crystals and pointed with the area surrounded by the "O-ring" (Figure $3 \mathrm{C}$ ). Whether the mesopores influence the crystal dissolution in $\mathrm{NH}_{4} \mathrm{~F}$ solution is not clear. We will provide a strong argument (vide supra) that the presence of such meso-sized pores is a clear evidence that the " $\mathrm{R}_{2}$ " zone is a defect and/or local-strain rich zone, being vulnerable to $\mathrm{NH}_{4} \mathrm{~F}$ treatment. In the present work, we named this phenomenon as a "defect-zoning".

\section{B) Al-zoning}

In addition to the defect-zoning discussed above, the EDX mapping reveals an Al-zoning in the ZSM-5 zeolite (Figure 4 and Table 1). Such an inhomogeneous distribution of $\mathrm{Al}$ in zeolite crystals is not new. Indeed, Al-zoning in FAU, ${ }^{[32,33]} \mathrm{TON},{ }^{[34]} \mathrm{MOR},{ }^{[35]}$ and especially for MFI type zeolites ${ }^{[22,36-39]}$ has been reported. A gradient distribution of framework $\mathrm{Al}$ increasing from the core to the rim is recorded often. However, the connection between Al-zoning and the spatial arrangement of organic and inorganic structural directing cations is not discussed up to now. In the present work, we show that the $\mathrm{Al}$ gradient distribution in the parent ZSM-5 sample is in good accordance with the spatial distribution of $\mathrm{C}$ and $\mathrm{Na}$. Specifically, higher $\mathrm{Si} / \mathrm{Al}$ ratio corresponds to higher $\mathrm{TPA}^{+}$and lower $\mathrm{Na}^{+}$cations, and conversely, lower $\mathrm{Si} / \mathrm{Al}$ ratio corresponds to lower TPA ${ }^{+}$and higher $\mathrm{Na}^{+}$cations (Table 1 ). Thus, the $\mathrm{Na}^{+}$cations favor the incorporation of $\mathrm{Al}$ in the MFI framework structure.

We further show that the applied $\mathrm{NH}_{4} \mathrm{~F}$ treatment results in a zeolite with higher Si/Al ratio than the parent sample due to the substantial dissolution of the $\mathrm{R}_{2}$ layer. The "unusual" Al-biased dissolution phenomenon, combined with the regioselective dissolution manifests that the dissolved part is relatively rich in Al. This can also be clearly seen from the difference in the chemical composition before and after $\mathrm{NH}_{4} \mathrm{~F}$ etching (Table 1). Noteworthy, the dissolved part should also correspond to a relatively $\mathrm{Na}^{+}$-richer and $\mathrm{TPA}^{+}$-poorer zone in the parent sample. Consequently, the $\mathrm{Na}^{+}$-occupied sites are more accessible, providing the etching fronts during the $\mathrm{NH}_{4} \mathrm{~F}$ etching of the $\mathrm{R}_{2}$ layer. This would mean that $\mathrm{TPA}^{+}(\mathrm{Si})$-richer and $\mathrm{Na}^{+}(\mathrm{Al})$-richer zones are alternatively distributed in the volume of the $\mathrm{R}_{2}$ layer, especially when the spatial homogeneity of the interstitial porosity pattern in this part is taken into consideration (Figure 1, Figure S4). These interstitial pores penetrated deep towards the $\mathrm{R}_{3}$ zone, corresponding to the removed parts (Figure 1C-D and Table 1). This observation is in accordance with the comment of the high TPA ${ }^{+}$content in $\mathrm{R}_{2}$ region of TPA-Z (Figure 4D). The probing of the porosity by $\mathrm{N}_{2}$ physisorption revealed that the accessible micropore volume of TPA-Z $\mathrm{Z}_{\mathrm{F}}$ is almost zero even after $\mathrm{Na}^{+}$-exchange (supporting information) (Figure S10). This is a clear sign that the micropores are practically blocked by $\mathrm{TPA}^{+}$.

Interestingly, such a spatial alternation of organic-cation-richer and inorganic-cation-richer zones in zeolite crystals 
is not an individual observation (more examples are provided in section 3.3). These findings are very important since there are great scientific and technological interests in the development of synthetic approach towards the incorporation of site-specific heteroatoms in zeolite framework. ${ }^{[40]}$ Especially, the combination of inorganic and organic cations was explored as a prevalent way to adjust the location of $\mathrm{Al}$ in specific framework tetrahedral positions. ${ }^{[31,41,42]}$ Our findings raise an important question regarding the spatial distribution of these "site-specific" heteroatoms at the mesoscale. In the present work, $\mathrm{Co}^{2+}$ was used to probe the $\mathrm{Al}$ distribution in the zeolite framework. The results show that the $\mathrm{Co} / \mathrm{Al}$ ratio determined by XRF is 0.37 for the $\mathrm{Co}^{2+}$-exchanged $\mathrm{Z}_{\mathrm{P}}$. It decreased to 0.23 for sample TPA- $\mathrm{Z}_{\mathrm{F}}$. This decreased $\mathrm{Co}^{2+}$ exchange capacity is a clear indication that the removed Al-richer zone is favorable for the accommodation of $\mathrm{Co}^{2+}$ cations. Thus, the $\mathrm{Al}$ sitting and $\mathrm{Al}$ zoning, originally discussed at the micro- and macro-scales, respectively, must be reconsidered carefully to understand the sitting and distribution of $\mathrm{Al}$ in zeolite frameworks.

\subsection{Defect-zoning and Al-zoning: a synthesis perspective}

At this stage, a comprehensive understanding of the internal architecture of zeolite crystals and the spatial distribution of atoms building the structure is related with the synthesis conditions. Therefore, the zeolite synthesis was thoroughly investigated.

\section{A) Defect-zoning}

The ZSM-5 zeolite was synthesized using both $\mathrm{TPA}^{+}$and $\mathrm{Na}^{+}$cations as structural directing agents. After the formation of a homogeneous solution consisting of both $\mathrm{TPA}^{+}$and $\mathrm{Na}^{+}$templates, the aluminum nitrate was added. The addition of the silica source (TEOS) after the complete dissolution of aluminum nitrate followed by hydrolysis resulted in the formation of homogenous sol comprising ultra-small nanosized aluminosilicate species (Figure S11). Prior to the hydrothermal treatment, the $\mathrm{pH}$ of the sol was 11.1. After $2 \mathrm{~h}$ crystallization at $443 \mathrm{~K}$, the solid products remain amorphous (Figure S12) containing uniform in size nanosized particle (Figure S13). The first crystalline particles appear after $\sim 3 \mathrm{~h}$ hydrothermal treatment; the particles do not have defined morphology until $4 \mathrm{~h}$ and they tend to form disordered floccules (Figure S14). Occasionally, we can find some particles with a rectangular shape that can be either amorphous or partially crystalline (Figure S14D). In line with the TEM observation, the XRD reveals the appearance of a crystalline product after $4 \mathrm{~h}$ (Figure S15). This is described as the first stage of the zeolite crystallization where the shaped particles contain the core $\mathrm{R}_{3}$ zone.

During the crystallization process, the $\mathrm{pH}$ of the suspension is increasing (Figure 5), which is favorable for increasing the supersaturation. As a result, the growth rate increases abruptly, resulting in crystals with large voids in a specific zone indicated by arrows in Figure $3 \mathrm{C}$, i.e. in the $\mathrm{R}_{2}$ zone in the middle part of the crystal. At this growth stage, the crystallinity of the solid products increases sharply (Figures 5, S12, S15 - S17), but the shape of zeolite particles is mostly irregular (Figure S18). The observed defect-zoning of the ZSM-5 crystals as described above is attributed to the aggregated growth in the second stage of zeolite crystallization. This stage is characterized by fast crystal growth, which could be not favorable for the surface relaxation of the particles after the oriented attachment events ${ }^{[14]}$, leading to the formation of layers rich in defects and local strains. 
At the end of the second stage, the nano-particles are mostly consumed (Figure S19A), but the high supersaturation of the crystallizing suspension is still retained. In the next third stage, the agglomeration process slows down, but the aggregates continue to grow mainly via the addition of lower-weight aluminosilicate species. ${ }^{[14]}$ The stage resulted in the formation of highly crystalline ZSM-5 zeolite (Figures 5) with a regular morphology (polyhedrons) and specific crystal faces (Figure S19B). At this stage, the nutrients are fully consumed, and the crystallization medium is in a dynamic equilibrium. The zeolite crystals have a multilevel core-shell structure, where each level corresponds to a particular crystallization stage. We noticed that the "egg-shell" structure (Figures 3D, 3E and Figure S3C) can be further subdivided in two layers. This can be attributed to the Ostwald ripening in the inhomogeneous and dynamic system.

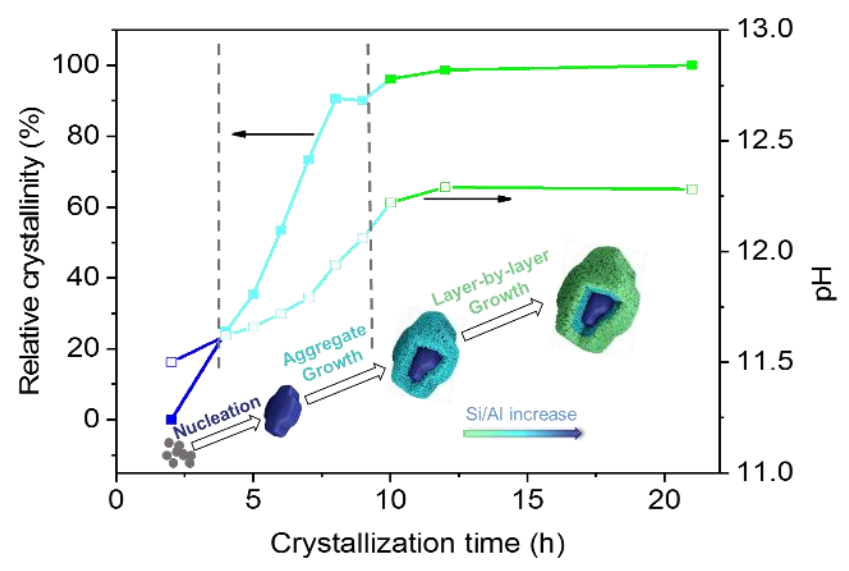

Figure 5. Relationship between relative crystallinity of ZSM-5 and the pH of the precursor suspension subjected to hydrothermal treatment at $443 \mathrm{~K}$ as a function of crystallization time.

\section{B) Al-zoning}

The Al-zoning in the present work has two-fold origin. (part B in section 3.1). The first is related to the classical gradient increase of framework $\mathrm{Al}$ content from the core to the rim of the crystals. The possible reason for this specific Al-zoning formation is as follows. During the zeolite synthesis, the precursor species go through several intermediate states, thus contributing to the aggregative growth of crystallites. ${ }^{[12]}$ Si-rich parts easily dissolve in alkaline medium compare to Al species. Probably, the higher solubility facilities the active evolution of the Si-rich nanoparticles, and promotes the preferential nucleation of zeolites in these silica-rich parts. ${ }^{[43]}$ Thus the $\mathrm{Si} / \mathrm{Al}$ ratio decreases gradually from the core to crystal periphery; these experimental findings are in a good agreement with previous reports. ${ }^{[22,44]} \mathrm{The} \mathrm{Si} / \mathrm{Al}$ ratio at the crystal periphery is slightly fluctuated (Table 1, Figure 4A). As determined by XPS, the Si/Al ratio is around 14.8. This is another indication that the crystallization is dynamically equilibrated, and the $\mathrm{Si} / \mathrm{Al}$ ratio at the periphery of zeolite crystals could deviate slightly. ${ }^{[43]}$ The second Al-zoning refers to the proposed alternation of $\mathrm{TPA}^{+}(\mathrm{Si})$-richer and $\mathrm{Na}^{+}$(Al)-richer zones within the same zeolite crystal. This is possible if we assume that the new crystallization event always is initiated in the relatively $\mathrm{TPA}^{+}$-rich zone, considering that $\mathrm{TPA}^{+}$is a strong template for the MFI zeolite formation. This points to the heterogeneity of the hydrogel containing the complex mixture of $\mathrm{Si}, \mathrm{Al}_{\mathrm{Na}}{ }^{+}$, and $\mathrm{TPA}^{+}$. The complexation between aluminosilicates and (in)organic cations can be intrinsically heterogeneous at a mesoscale due to the size and charge density difference between $\mathrm{TPA}^{+}$and $\mathrm{Na}^{+}$. Accordingly, a similar-sized amorphous aluminosilicate 
entity (particles or low-weight molecules) can accommodate a higher number of $\mathrm{Na}^{+}$and $\mathrm{Al}$. These entities have a balanced local structure that can be preserved in the final crystallites.

\subsection{Are the defect-zoning and Al-zoning general phenomena?}

The observations above encourage an investigation on whether the finding of defect-zoning and Al-zoning are a general phenomenon or not. For this purpose, we revisited the $\mathrm{NH}_{4} \mathrm{~F}$ etching of the two commercial ZSM-5 zeolites, which we have studied before. ${ }^{[7]}$ In addition, we synthesized two ZSM-5 zeolite samples using either solely TPAOH (ZSM-5-H1) or a combination of TPAOH and $\mathrm{KOH}(\mathrm{ZSM}-5-\mathrm{H} 2)$ as structure-directing agents. Then the same $\mathrm{NH}_{4} \mathrm{~F}$ etching was carried out on the zeolites before and after removing the organic template (Supporting Information). $\mathrm{K}^{+}$was specifically selected since it is considered as a structure-breaking cation in the ZSM-5 zeolite synthesis. ${ }^{[45]}$

The main findings from the dissolution studies are summarized here. For the two commercial samples, while they are already in $\mathrm{NH}_{4}{ }^{+}$-form (ZSM-5-II offered by Clariant, $\mathrm{Si} / \mathrm{Al}=21$ ) or $\mathrm{H}$-form (ZSM-5-I from Grace Davison, $\mathrm{Si} / \mathrm{Al}=$ 16) with the synthesis history unknown, the outer layers of the zeolite crystals are always more resistant to $\mathrm{NH}_{4} \mathrm{~F}$ etching $^{[30]}$ (Figure S20). Although there are no distinct boundaries separating different crystal layers as mentioned above, the sharp difference in solubility between crystal interior and outer layers is a clear indication for defect-zoning and a different crystallization behavior. ${ }^{[30]}$ The time-resolved dissolution of these two samples didn't change their Si/Al ratio. ${ }^{[7]}$

The $\mathrm{NH}_{4} \mathrm{~F}$ etching of the calcined ZSM-5-H1 shows similar selected-area dissolution behavior, ${ }^{[7]}$ characterized by substantially dissolved crystal interior and less impacted rim (Figures S21-S22) with a marginal change of Si/Al ratio from 44.8 to 43.5 . In contrast, the $\mathrm{NH}_{4} \mathrm{~F}$ etching of the as-synthesized ZSM-5-H1 sample resulted in a greater change of the $\mathrm{Si} / \mathrm{Al}$ ratio (44.8 vs 40.4). The etched ZSM-5-H1 sample was segmented along extended grain boundary, while the bulk crystals are largely preserved due to the protection of the $\mathrm{TPA}^{+}$cations. Noticeably, the core of crystals is preferentially removed (Figures S23-S24). Putting all together, it would mean that the preferentially removed core part is relatively Si-rich, pointing again to the preferential nucleation in the Si-rich zone. The ZSM-5-H2 zeolite was also treated by $\mathrm{NH}_{4} \mathrm{~F}$ with and without the protection of $\mathrm{TPA}^{+}$. Again, the dissolution of the calcined sample changes marginally the $\mathrm{Si} / \mathrm{Al}$ ratio, which is in agreement with the previous results. ${ }^{[7]}$ On the other hand, the dissolution of the as-synthesized ZSM-5-H2 sample increases the $\mathrm{Si} / \mathrm{Al}$ ratio from 41.4 to 55.1. Moreover, the etched sample shows a distinct regioselective dissolution pattern and a core-shell structure (Figure S25), similar to the ( $\mathrm{PPA}^{+}+\mathrm{Na}^{+}$) system but on a larger scale. Noting that in principle, only the freely exchangeable $\mathrm{K}^{+}$occupied sites are available etching pits as the protective effect of $\mathrm{TPA}^{+}$has been repetitively confirmed.

These results show that, while the distinct multiple core-shell structure (Figure 1) might be case-specific, defect-zoning, and Al-zoning are phenomena that can be generalized. The distinction of the multiple core-shell structure reported here points toward a three-stage crystallization process. Nucleation will be favored by the stronger structural directing cations in the Si-rich region. Depending on the geometric and electronic properties, Al zoning at both macroand meso-scale will be induced. Depending on the supersaturation of the crystallizing system, defect-zoning can be settled or alleviated.

\section{Conclusion}

In the present work, the inner heterogeneity of zeolite crystals as defect-zoning and Al-zoning at both macro- and meso-scales is revealed. $\mathrm{NH}_{4} \mathrm{~F}$ etching is used as an unbiased tool for structure disassembly of ZSM-5 zeolite crystals with (as-synthesized) and without (calcined) organic structural directing agent $\left(\mathrm{TPA}^{+}\right)$. As revealed by the $\mathrm{NH}_{4} \mathrm{~F}$ etching, the as-synthesized pseudo-single ZSM-5 crystals have a defect-zoning resulting essentially in an egg-like multiple 
core-shell structure. The innermost core, the "egg-yolk" part of the multilayer structure, is surrounded by a zeolite layer rich in defects, which forms the "egg-white" part in the middle of the pseudo-single crystal. It is preferentially dissolved by $\mathrm{NH}_{4} \mathrm{~F}$ as a result of the higher defect concentration in this layer. The outermost part of the zeolite crystals, the "egg-shell", is more resistant than the "egg-white" thanks to the lower defect content.

Several studies have reported on the etching of ZSM-5 zeolite leading to similar Al-zoning. ${ }^{[38,46]}$ Further, we revealed that the compact core has the highest content of $\mathrm{Si}$ and $\mathrm{TPA}^{+}$and the lowest concentration of $\mathrm{Na}^{+}$. Both the $\mathrm{Si} / \mathrm{Al}$ ratio and $\mathrm{TPA}^{+}$content keep decreasing from the core to the crystal periphery, accompanied by a continuous increase in $\mathrm{Na}^{+}$concentration. Thus, a clear map of spatial elements distribution was obtained, and the relation between Al-zoning and charge-compensating cations (structure-directing agents) was observed for the first time.

Both the defect-zoning and Al-zoning are bound to the crystallization in a substantially inhomogeneous and dynamic supersaturation environment. The crystallization process of zeolite is described as a three-stage process: Stage 1: nucleation starts preferentially in the Si-rich part, templated by $\mathrm{TPA}^{+}$, due to the higher solubility of silica in the alkaline medium; Stage 2: rapid amorphous-to-crystalline transformation process resulting in a fast increase of the apparent crystallinity, and fast accumulation of units including nano-particles, low-weight molecules, etc. This fast crystallization is combined with a delay in their post-attachment to the growing crystals resulting in the formation of defects in the zeolite, thus making them vulnerable to $\mathrm{NH}_{4} \mathrm{~F}$ treatment. Meanwhile, more $\mathrm{Al}$ is incorporated in the zeolite framework due to the higher solubility of the Al-containing species with the increased alkalinity of the suspension. Thus the $\mathrm{Na}^{+}$ content in the zeolite crystals increased accordingly to compensate the framework negative charges. Stage 3: the last state of crystallization, is a near-equilibrium process dominated via layer-by-layer crystal growth, leading to the formation of the surface crust of the crystals with characteristic MFI morphology.

The exploitation of the dissolution behavior of several ZSM-5 zeolites synthesized in systems containing different templates $\left(\mathrm{TPA}^{+}-\mathrm{Na}^{+}\right.$, pure TPA, $\left.\mathrm{TPA}^{+}-\mathrm{K}^{+}\right)$further supports the ubiquitous defect-zoning and Al-zoning phenomena. The in-depth understanding of zeolite dissolution behavior, the inner heterogeneity and chemical gradient (elemental distribution) of zeolite crystals, and the deduced zeolite crystallization mechanism provide valuable information for further tailored-design of zeolite crystals with pre-determined properties.

\section{Conflicts of interest}

The authors declare no competing financial interest

\section{Acknowledgements}

Z.Q. acknowledges the support from NSFC21706285, Qingdao Applied Basic Research Project (19-6-2-70-cg), the Fundamental Research Funds for the Central Universities (18CX02013A); S.M. acknowledges the support from NSFC21975285 and Thousand Talents Program for Foreign Experts (WQ20152100316); Z.Q. and S.M. acknowledge the support from NSFC 21991090, NSFC21991091. The authors acknowledge funding from the Sino-French joint laboratory "Zeolites".

\section{References}

[1] Jin Z. Wang L. Zuidema E., Mondal K., Zhang M., Zhang J., Wang C., Meng X., Yang H., Mesters C., Xiao F. S., Science 2020, 367 (6474), 193-197.

[2] Dusselier M., Davis M. E., Chem. Rev. 2018, 118 (11), 5265-5329.

[3] Yang M., Fan D., Wei Y. X., Tian P., Liu Z. M., Adv. Mater. 2019, 31 (50), 1902181.

[4] Do M. H., Wang T., Cheng D. G., Chen F., Zhan X., Gong J., J. Mater. Chem. A 2014, 2 (35), 14360-14370. 
[5] De Yoreo J. J., Gilbert P., Sommerdijk N., Penn R. L., Whitelam S., Joester D., Zhang H. Z., Rimer J. D., Navrotsky A., Banfield J. F., Wallace A. F., Michel F. M., Meldrum F. C., Colfen H., Dove P. M., Science 2015 , 349 (6247).

[6] Ivanova I. I., Kolyagin Y. G., Kasyanov I. A., Yakimov A. V., Bok T. O., Zarubin D. N., Angew. Chem. Int. Ed. 2017, 56 (48), 15346-15349.

[7] Qin Z., Melinte G., Gilson J. P., Jaber M., Bozhilov K., Boullay P., Mintova S., Ersen O., Valtchev V., Angew. Chem. Int. Ed. 2016, 55 (48), 15273-15276.

[8] Burkett S. L., Davis M. E., Chem. Mater. 1995, 7 (5), 920-928.

[9] Mintova S, Olson N H, Valtchev V, et al. Mechanism of zeolite A nanocrystal growth from colloids at room temperature[J]. Science, 1999, 283(5404): 958-960.

[10] Kirschhock C. E. A., Buschmann V., Kremer S., Ravishankar R., Houssin C. J. Y., Mojet B. L., van Santen R. A., Grobet P. J., Jacobs P. A., Martens J. A., Angew. Chem. Int. Ed. 2001, 40 (14), 2637-2640.

[11] Epping J., Chmelka B., Curr. Opin. Colloid Interface Sci. 2006, 11 (2-3), 81-117.

[12] Davis T. M., Drews T. O., Ramanan H., He C., Dong J., Schnableg-ger H., Katsoulakis M. A., Kokkoli E., McCormick A. V., Penn R. L., Tsapatsis M., Nat. Mater. 2006, 5 (5), 400-408.

[13] Ren N., Subotić B., Bronić J., Tang Y., Dutour Sikirić M., Mišić T., Svetličić V., Bosnar S., Antonić Jelić T., Chem. Mater. 2012, 24 (10), 1726-1737.

[14] Lupulescu A. I., Rimer J. D., Science 2014, 344 (6185), 729-732.

[15] Kumar M., Choudhary M. K., Rimer J. D., Nat. Commun. 2018, 9, 2129.

[16] Choudhary M. K., Kumar M., Rimer J. D., Angew. Chem. Int. Ed. 2019, 58 (44), 15712-15716.

[17] Kumar M., Luo H., Roman-Leshkov Y., Rimer J. D., J. Am. Chem. Soc. 2015, 137 (40), 13007-13017.

[18] Wang C. F., Zhang L., Huang X., Zhu Y. F., Li G., Gu Q. F., Chen J. Y., Ma L. G., Li X. J., He Q. H., Xu J. B., Sun Q., Song C. Q., Peng M., Sun J. L., Ma D., Nat. Commun. 2019, 10, 8.

[19] Karwacki L., Kox M. H. F., de Winter D. A. M., Drury M. R., Meeldijk J. D., Stavitski E., Schmidt W., Mertens M., Cubillas P., John N., Chan A., Kahn N., Bare S. R., Anderson M., Kornatowski J., Weckhuysen B. M., Nat. Mater. 2009, 8 (12), 959-965.

[20] Perea D. E., Arslan I., Liu J., Ristanovic Z., Kovarik L., Arey B. W., Lercher J. A., Bare S. R., Weckhuysen B. M., Nat. Commun. 2015, 6, 7589.

[21] Schmidt J. E., Hendriks F. C., Lutz M., Post L. C., Fu D., Weckhuysen B. M., Chemphyschem 2018,19 (4), 367-372.

[22] Li T., Krumeich F., Chen M., Ma Z., van Bokhoven J. A., Phys. Chem. Chem. Phys. 2020, 22 (2), $734-739$.

[23] Cho H. S., Miyasaka K., Kim H., Kubota Y., Takata M., Kitagawa S., Ryoo R., Terasaki O., J. Phys. Chem. C 2012, 116 (48), 25300-25308.

[24] Mitchell S., Pinar A. B., Kenvin J., Crivelli P., Kaerger J., Perez-Ramirez J., Nat. Commun. $2015,6,8633$.

[25] Grand J., Talapaneni S. N., Vicente A., Fernandez C., Dib E., Aleksandrov H. A., Vayssilov G. N., Retoux R., Boullay P., Gilson J. P., Valtchev V., Mintova S., Nat. Mater. 2017, 16 (10), 1010-1015.

[26] Prodinger S., Vjunov A., Hu J. Z., Fulton J. L., Carnaioni D. M., Derewinski M. A., Lercher J. A., Chem. Mater. 2018, 30 (3), 888-897.

[27] Valtchev V. P., Bozhilov K. N., J. Am. Chem. Soc. 2005, 127 (46), 16171-16177. 
[28] Qin Z., H. Leila, Shen Y., Van Daele S., Boullay P., Ruaux V., Mintova S., Gilson J.-P., Valtchev V., J. Mater. Chem. A 2020, 8 (7), 3621-3631.

[29] Qin Z., Cychosz K. A., Melinte G., El Siblani H., Gilson J.-P., Thommes M., Fernandez C., Mintova S., Ersen O., Valtchev V., J. Am. Chem. Soc. 2017, 139 (48), 17273-17276.

[30] Qin Z., Pinard L., Benghalem M. A., Daou T. J., Melinte G., Ersen O., Asahina S., Gilson J.-P., Valtchev V., Chem. Mater. 2019, 31 (13), 4639-4648.

[31] Chawla A., Li R., Jain R., Clark R. J., Sutjianto J. G., Palmer J. C., Rimer J. D., Mol. Syst. Des. Eng. 2018,3 (1), 159-170.

[32] Lutz W., Kurzhals R., Kryukova G., Enke D., Weber M., Heidemann D., Z. Anorg. Allg. Chem. 2010, 636, 1497-1505.

[33] Ohsuna T., Terasaki O., Alfredsson V., Bovin J.-O., Watanabe D., Carr S. W., Anderson M. W., P. Roy. Soc. Lond. A Mat. 1996, 452, 715-740.

[34] Hayasaka K., Liang D., Huybrechts W., De Waele B. R., Houthoofd K. J., Eloy P., Gaigneaux E. M., van Tendeloo G., Thybaut J. W., Marin G. B., Denayer J. F. M., Baron G. V., Jacobs P. A., Kirschhock C. E. A., Martens J. A., Chem. Eur. J. 2007, 13, 10070-10077.

[35] Terasaki O., Ohsuna T., Catal. today 1995, 23, 201-218.

[36] Von Ballmoos R., Meier W., Nature 1981, 289, 782-783.

[37] Dessau R., Valyocsik E., Goeke N., Zeolites 1992, 12, 776-779.

[38] Danilina N., Krumeich F., Castelanelli S. A., van Bokhoven J. A., J. Phys. Chem. C 2010, 114, 6640-6645.

[39] Ristanović Z., Hofmann J. P., Deka U., Schülli T. U., Rohnke M., Beale A. M., Weckhuysen B. M., Angew. Chem. Int. Ed. 2013, 125, 13624-13628.

[40] Davis M. E. In Catalysis by Crystalline Microporous Materials, Catalysis in Chemistry and Biology: Proceedings of the 24th International Solvay Conference on Chemistry, World Scientific: 2018; p. 137.

[41] Dedecek J., Balgová V., Pashkova V., Klein P., Wichterlová B., Chem. Mater. 2012, 24 (16), 3231-3239.

[42] Di Iorio J. R., Gounder R., Chem. Mater. 2016, 28 (7), 2236-2247.

[43] Derouane E. G., Determmerie S., Gabelica Z., Blom N., Appl. Catal. 1981, 1, 201-224.

[44] Schmidt J. E., Poplawsky J. D., Mazumder B., Attila O., Fu D., De Winter D. A. M., Meirer F., Bare S. R., Weckhuysen B. M., Angew. Chem. Int. Ed. 2016, 55, 11173-11177.

[45] Gabelica Z., Blom N., Derouane E. G., Appl. Catal. 1983, 5, 227-248.[46] Groen J. C., Bach T., Ziese U., Donk A. M. P., De Jong K. P., Moulijn J. A., and Pérez-Ramírez J., J. Am. Chem. Soc. 2005, 127(31), 10792-10793. 